\title{
Long-term management of patients with celiac disease: Current practices of gastroenterologists in Canada
}

\author{
Jocelyn Anne Silvester MD PhD, Mohsin Rashid MBBS MEd FRCPC
}

\begin{abstract}
JA Silvester, M Rashid. Long-term management of patients with celiac disease: Current practices of gastroenterologists in Canada. Can J Gastroenterol 2010;24(8):499-509.
\end{abstract}

BACKGROUND: Long-term follow-up of patients with celiac disease is important for monitoring their clinical status, dietary compliance and complications.

AIM: To examine the current practices of Canadian gastroenterologists providing long-term care to patients with celiac disease.

METHODS: All gastroenterologists in Canada $(n=585)$ were surveyed regarding their practice demographics, familiarity with celiac disease practice guidelines, and follow-up clinical examination and investigations.

RESULTS: Of the 585 surveys mailed to gastroenterologists, 567 were expected to be returned. A total of 242 completed surveys (43\%) were received. Of these, 237 (184 adult, 51 pediatric and two mixed) had an active practice that included patients with celiac disease. Long-term follow-up care was provided routinely by $76 \%$ of respondents. Follow-up consisted of annual clinic visits (67\%), dietary review $(77 \%)$, reinforcement of the need for adherence to a gluten-free diet (90\%) and recommending membership in an advocacy group (65\%). Physical examination was performed by $78 \%$; most ordered laboratory tests including serology (65\%).

Adult gastroenterologists performed routine follow-up intestinal biopsy more often than their pediatric counterparts (46\% versus $10 \%$ ), but performed serology less frequently (48\% versus $86 \%$ ). Pediatric patients were more likely to be followed by a multidisciplinary team. All pediatric gastroenterologists were familiar with at least one celiac disease practice guideline, whereas $15 \%$ of adult gastroenterologists were not familiar with any practice guideline. The majority of gastroenterologists who did not routinely provide follow-up expected care to be provided by the patient's primary physician (86\%).

CONCLUSIONS: Most gastroenterologists in Canada who responded to the survey provided long-term follow-up care to patients with celiac disease. The diverse practices reported underscore the need to develop consensus-based guidelines for long-term care of these patients.

Key Words: Celiac disease; Follow-up; Gluten-free diet; Management

Cliac disease is a chronic gastrointestinal disorder in which gluten (a protein in wheat, barley and rye) causes damage to the small intestinal mucosa by an autoimmune mechanism in genetically susceptible individuals. It is a common disorder estimated to affect approximately $1 \%$ of the North American population (1). Presently, the only effective treatment for celiac disease is lifelong adherence to a strict gluten-free diet. In the years since serological screening tests for celiac disease became widely available, more individuals with this disorder are being recognized and diagnosed (2). Consequently, there is an ever-growing group of individuals with celiac disease who have been advised to follow a gluten-free diet, and require long-term monitoring and follow-up of their condition.

\section{La prise en charge à long terme des patients ayant une maladie coliaque : Les pratiques actuelles des gastroentérologues du Canada}

HISTORIQUE : Le suivi à long terme des patients ayant une maladie cœliaque est important pour surveiller leur état clinique, leur respect des restrictions alimentaires et les complications.

OBJECTIF : Examiner les pratiques actuelles des gastroentérologues canadiens qui dispensent des soins à long terme aux patients ayant une maladie cœliaque.

MÉTHODOLOGIE : Tous les gastroentérologues du Canada $(n=585)$ ont été sondés au sujet de la démographie de leur pratique, de leur familiarité avec les lignes de pratique de la maladie coeliaque, de l'examen clinique de suivi et des explorations.

RÉSULTATS : Sur les 585 sondages postés aux gastroentérologues, on s'attendait que 567 soient remplis. Au total, les chercheurs en ont reçu 242 (43\%). De ce nombre, 237 (184 pour adultes, 51 pour la population pédiatrique et deux mixtes) avaient une pratique active qui incluait des patients ayant une maladie cœliaque. Les soins de suivi à long terme étaient assurés systématiquement par $76 \%$ des répondants. Le suivi était constitué de visites cliniques annuelles (67\%), de l'examen du régime alimentaire (77\%), du renforcement de la nécessité de respecter un régime sans gluten (90\%) et de la recommandation d'adhérer à un groupe de défense d'intérêts (65\%). L'examen physique était effectué par $78 \%$ d'entre eux. La plupart demandaient des tests de laboratoire, y compris une sérologie (65\%).

Les gastroentérologues pour adultes ont effectué des biopsies intestinales de suivi systématiques plus souvent que leurs homologues pédiatres (46\% par rapport à $10 \%$ ), mais moins de sérologies (48\% par rapport à $86 \%$ ). La population pédiatrique était plus susceptible d'être suivie par une équipe multidisciplinaire. Tous les gastroentérologues pédiatres connaissaient au moins une ligne de pratique sur la maladie cœliaque, tandis que $15 \%$ des gastroentérologues pour adultes n'en connaissaient aucune. La majorité des gastroentérologues qui n'effectuaient pas de suivi systématique s'attendaient que les soins soient assurés par le médecin traitant du patient (86\%).

CONCLUSIONS : La plupart des gastroentérologues du Canada qui ont répondu au questionnaire dispensaient des soins de suivi à long terme aux patients ayant une maladie coeliaque. Les diverses pratiques déclarées soulignent la nécessité de préparer des lignes directrices consensuelles pour le suivi à long terme de ces patients.

The presentation of celiac disease (both classic and atypical) and identification of affected individuals have been, and continue to be, rigorously investigated. In contrast, the appropriate format, frequency and content of long-term follow-up of patients with celiac disease is not supported by a strong evidence base, and current practice guidelines endorse a broad range of practices (3-7). The actual practices of gastroenterologists with respect to long-term follow-up of their patients diagnosed with celiac disease are largely unknown. Consequently, it is not clear whether any of the guidelines are currently being followed or whether current practices are supported by the available evidence.

Given the increasing rate at which the diagnosis of celiac disease is being made, this question is ever more important, not

Division of Gastroenterology and Nutrition, Department of Pediatrics, Faculty of Medicine, Dalhousie University, Halifax, Nova Scotia

Correspondence: Dr Mohsin Rashid, Division of Gastroenterology, IWK Health Centre, 5850 University Avenue, Halifax,

Nova Scotia B3K 6R8. Telephone 902-470-8746, fax 902-470-7249, e-mail mohsin.rashid@iwk.nshealth.ca

Received for publication September 29, 2009. Accepted December 1, 2009 
only for resource allocation, but also for the health of the individual patient who risks harm when nonevidence-based tests are performed routinely, and when tests that may identify a treatable complication of celiac disease are not performed.

The purpose of the present study was to investigate the practices of Canadian gastroenterologists who provide care to patients with celiac disease.

\section{METHODS}

The study population included all gastroenterologists currently practicing in Canada. Mailing addresses were collected from several sources. The online registers of provincial licensing authorities (British Columbia, Alberta, Manitoba, Ontario, New Brunswick, Newfoundland and Labrador, Nova Scotia and Prince Edward Island) were searched for specialists in gastroenterology and pediatric gastroenterology. Registrants whose addresses were outside of Canada or who were 'not in active practice' were excluded. For Saskatchewan, information was provided by telephone by the College of Physicians and Surgeons of Saskatchewan. For Quebec, the Canadian Medical Directory (8) was used because physician information was not directly available from the Collège des Médecins du Québec. The addresses were cross-checked with the published listings in the 2007 membership directory of the American Gastroenterological Association (AGA). To ensure that pediatric gastroenterologists who may be registered as pediatricians rather than pediatric gastroenterologists were included, all lists were cross-referenced with the 2007 membership directory of the North American Society for Pediatric Gastroenterology, Hepatology and Nutrition (NASPGHAN).

A self-administered survey was developed with questions that were based on current practice guidelines and recommendations for the long-term follow-up of individuals with celiac disease $(4-7,9)$, and results from the Canadian Celiac Health Survey (10-12), which provided insight into preferred sources of dietary information for adults and children with celiac disease. The questionnaire contained 86 items pertaining to physician and practice characteristics, familiarity with celiac disease practice guidelines and current practices in terms of clinical assessment, investigations and follow-up management.

The survey was mailed to all potential participants along with a postage-paid return envelope. Participants were asked to return the survey within two weeks. All potential participants received a second mailing sent three weeks after the initial mailing because the surveys were anonymous and were not coded in a way that could link them to the participants.

Data were analysed using SPSS version 15.0 (SPSS Inc, USA) for Windows (Microsoft Corporation, USA). The $\chi^{2}$ test was used for comparison of frequencies, and a Fisher's two-sided exact test result of $\mathrm{P}<0.05$ was considered to be statistically significant. Common OR was estimated, calculated using the Mantel-Haenszel test.

The study was approved by the Research Ethics Board of the IWK Health Centre, Dalhousie University (Halifax, Nova Scotia).

\section{RESULTS}

A list of 585 gastroenterologists actively practicing in Canada was compiled from the sources listed above. Of the surveys sent, 11 were returned because of an invalid address; a search of printed and online sources did not yield an alternative address. Six respondents indicated that they were retired or no longer actively practicing. One individual reported having been contacted at practices in two provinces in the same region. Therefore, of the 585 surveys mailed, only 567 surveys were expected to be returned.

A total of 242 completed surveys were received from gastroenterologists in active practice, for an overall response rate of $42.7 \%$. These included one survey from a hepatologist who did not treat patients with celiac disease and did not indicate a region. Six respondents identified having a mixed practice that included both adult and pediatric patients, and were asked to estimate the proportion of patients in each group. Those who had a practice with $75 \%$ or more adult or pediatric patients were included in subsequent analyses as either adult or pediatric gastroenterologists, respectively. One individual who did not identify the practice mix did not follow patients with celiac disease, and another who had a 60\%/40\% distribution was not classified. Because of these two physicians with mixed practices, the total number of gastroenterologists was not equal to the sum of the adult and pediatric gastroenterologists.

To investigate regional differences, participants were asked to identify their geographical region as West (British Columbia, Alberta, Saskatchewan and Manitoba), Central (Ontario and Quebec), Atlantic (Nova Scotia, New Brunswick, Prince Edward Island, and Newfoundland and Labrador) or North (Yukon Territory, Northwest Territories and Nunavut). There were no respondents who were based in the North, a sparsely populated region with no tertiary care centres. Table 1 shows the number of surveys mailed, the number of completed surveys expected to be returned, and the response rate in each region and practice group. The response rate was higher for the Atlantic region $(76 \%)$ than for the West $(44 \%)$ and Central $(38 \%)$ regions of Canada. A greater proportion of pediatric (57\%) than adult gastroenterologists (38\%) responded.

\section{Respondent characteristics}

Of the 242 responding gastroenterologists in active practice, five had an academic practice that did not include patients with celiac disease. Of the remaining 237 gastroenterologists, $184 \mathrm{had}$ a practice that was primarily adult patients, 51 had a practice that was primarily pediatric patients and two had a mixed practice. The characteristics of respondents whose practice included patients with celiac disease are shown in Table 2. Approximately one-half of all respondents had an academic practice, with significantly more pediatric than adult gastroenterologists in academic practice ( $86 \%$ versus $43 \%$; OR 8.4; 95\% Cl 3.6 to 20; $\mathrm{P}<0.0001)$. Each region had a similar proportion of adult and pediatric gastroenterologists.

Overall, nearly $40 \%$ of respondents had been in practice for 10 years or less. As a group, pediatric gastroenterologists who responded had significantly fewer cumulative years in practice than their adult counterparts. The majority of respondents had between 11 and 100 patients with celiac disease in their practice.

\section{Sources of information}

Professional conferences (81\%), medical journals (79\%) and practice guidelines $(67 \%)$ were the most common sources of information about celiac disease. Pediatric gastroenterologists 
TABLE 1

Response rate according to region and gastroenterologist type

\begin{tabular}{|c|c|c|c|c|c|}
\hline \multirow[b]{2}{*}{ Region } & \multicolumn{3}{|c|}{ Surveys } & \multicolumn{2}{|c|}{$\begin{array}{c}\text { Gastroenterologist }{ }^{\star} \text { response } \\
\text { rate, } \mathrm{n}(\%)\end{array}$} \\
\hline & $\begin{array}{l}\text { Mailed, } \\
\mathrm{n}\end{array}$ & $\begin{array}{c}\text { Expected } \\
n\end{array}$ & $\begin{array}{l}\text { Received, } \\
\text { n (\%) }\end{array}$ & Adult & Pediatric \\
\hline West & 190 & 184 & $81(44)$ & $65(42)$ & $16(76)$ \\
\hline Central & 360 & 349 & $134(38)$ & $100(34)$ & $33(57)$ \\
\hline Atlantic & 35 & 34 & $26(76)$ & $21(72)$ & 5 (100) \\
\hline Total & 585 & 567 & $242(43)^{\ddagger}$ & $186(38)$ & $54(57)^{\S}$ \\
\hline
\end{tabular}

${ }^{*}$ Respondents who indicated a mixed practice were classified as adult or pediatric gastroenterologists if $75 \%$ or more of their practice was either adult or pediatric, respectively; ${ }^{\dagger}$ Twelve surveys that were returned because of an invalid address and the six individuals who responded that they were retired or no longer practicing were excluded to determine the total number of surveys expected; ${ }^{\ddagger}$ Includes one respondent who did not treat patients with celiac disease and did not provide demographic information; ${ }^{\S}$ Excludes one respondent who did not provide demographic information and another whose practice distribution was 60:40 and could not be classified as either adult or pediatric (see Results)

were more likely to use conferences and practice guidelines than adult gastroenterologists, and also used practice guidelines more often than adult gastroenterologists who had a primarily academic practice $(86 \%$ versus $66 \% ; \mathrm{P}<0.05)$. With respect to specific practice guidelines, significantly more adult gastroenterologists were familiar with the AGA guidelines; pediatric gastroenterologists were more familiar with the NASPGHAN guidelines. The 27 respondents (11\%) who were not familiar with any practice guideline were all adult gastroenterologists. Slightly more than one-quarter of respondents listed the Canadian Celiac Association (CCA) as a source of information.

\section{Duodenal biopsy practices}

Participants were asked whether they routinely performed follow-up duodenal biopsy after diagnosis and their indications for biopsy during long-term follow-up. With respect to routine follow-up biopsy after initiation of a gluten-free diet, 38\% almost always and 36\% almost never performed a follow-up duodenal biopsy. The practice was significantly more common among adult than pediatric gastroenterologists ( $46 \%$ versus 10\%; OR $7.8 ; 95 \%$ CI 2.9 to 22). There was no association between routine biopsy to confirm normal villous architecture and years in practice. The other $26 \%$ only performed a repeat duodenal biopsy in select cases. The most common indications were incomplete or inadequate response to a gluten-free diet (69\%), persistently abnormal serology or other laboratory values $(18 \%)$ and normal serology at diagnosis $(9 \%)$.

The most common indication for duodenal biopsy during long-term follow-up was ongoing symptoms despite claiming adherence to a gluten-free diet (76\%). Other reasons included concern of continued consumption of gluten $(30 \%)$, concern of consumption with negative serology (22\%) and to confirm normal histology (25\%). Adult gastroenterologists were significantly more likely than pediatric gastroenterologists to perform a biopsy because of concern of continued consumption of gluten $(34 \%$ versus $16 \% ; \mathrm{P}<0.05)$.

\section{Use of serology}

Participants were asked whether and when they performed follow-up serology. The majority of respondents (56\%) almost
TABLE 2

Characteristics of respondents whose practice included patients with celiac disease

\begin{tabular}{|c|c|c|c|c|}
\hline & \multicolumn{3}{|c|}{ Gastroenterologists } & \multirow[b]{2}{*}{$\mathrm{P}^{*}$} \\
\hline & $\begin{array}{c}\text { Total } \\
(\mathrm{n}=237)\end{array}$ & $\begin{array}{c}\text { Adult } \\
(n=184)\end{array}$ & $\begin{array}{c}\text { Pediatric } \\
(n=51)\end{array}$ & \\
\hline \multicolumn{2}{|l|}{ Practice type } & & & $<0.01$ \\
\hline Academic & $124(52)$ & $79(43)$ & $44(86)$ & \\
\hline Private & $71(30)$ & $66(36)$ & $4(8)$ & \\
\hline Mixed & $52(18)$ & $39(21)$ & $3(6)$ & \\
\hline \multicolumn{2}{|l|}{ Location } & & & 0.62 \\
\hline West & $81(34)$ & 64 (35) & $16(31)$ & \\
\hline Central & $131(55)$ & $99(54)$ & $31(61)$ & \\
\hline East & $25(11)$ & $21(11)$ & $4(8)$ & \\
\hline \multicolumn{2}{|l|}{ Years in practice } & & & $<0.05$ \\
\hline $0-10$ & $90(38)$ & $64(35)$ & $26(51)$ & \\
\hline $11-20$ & $67(28)$ & $52(28)$ & $14(27)$ & \\
\hline $21-30$ & $47(20)$ & $36(20)$ & $10(20)$ & \\
\hline$>30$ & $33(14)$ & $32(17)$ & $1(2)$ & \\
\hline \multicolumn{2}{|l|}{ Celiac disease patients } & & & 0.24 \\
\hline $1-10$ & $44(19)$ & $35(19)$ & $9(18)$ & \\
\hline $11-100$ & $170(72)$ & $134(73)$ & $34(66)$ & \\
\hline $101-200$ & $12(5)$ & $7(4)$ & $5(10)$ & \\
\hline$>200$ & $5(2)$ & $3(2)$ & $2(4)$ & \\
\hline No answer & $6(2)$ & $5(3)$ & $1(2)$ & \\
\hline \multicolumn{2}{|c|}{ Follow celiac disease patients } & & & 0.09 \\
\hline Yes & $181(76)$ & $138(75)$ & $42(82)$ & \\
\hline No & $49(21)$ & $43(23)$ & $6(12)$ & \\
\hline Yes and no & $7(3)$ & $3(2)$ & $3(6)$ & \\
\hline \multicolumn{5}{|l|}{ Information sources } \\
\hline Conferences & $193(81)$ & $142(77)$ & $49(96)$ & $<0.01$ \\
\hline Colleagues & $124(52)$ & $92(50)$ & $31(61)$ & 0.17 \\
\hline Practice guidelines & $158(67)$ & $113(61)$ & $44(86)$ & $<0.01$ \\
\hline Medical journals & $188(79)$ & $147(80)$ & $39(77)$ & 0.60 \\
\hline CCA & $63(27)$ & $47(26)$ & $15(29)$ & 0.58 \\
\hline Other celiac association & $17(7)$ & $12(7)$ & $4(8)$ & 0.74 \\
\hline \multicolumn{5}{|l|}{ Practice guideline familiarity } \\
\hline AGA & $187(79)$ & $152(83)$ & $34(67)$ & $<0.05$ \\
\hline NASPGHAN & $67(28)$ & $16(9)$ & $50(98)$ & $<0.01$ \\
\hline $\mathrm{NIH}$ & $43(18)$ & $30(16)$ & $12(24)$ & 0.23 \\
\hline BSG & $17(7)$ & $13(7)$ & $4(8)$ & 0.85 \\
\hline PCSG & $5(2)$ & $5(3)$ & $0(0)$ & 0.23 \\
\hline WGO & $22(9)$ & $18(10)$ & $4(8)$ & 0.67 \\
\hline None & 27 (11) & 27 (15) & $0(0)$ & $<0.01$ \\
\hline
\end{tabular}

Data presented as $n(\%)$ unless indicated otherwise. *Comparison between adult and pediatric gastroenterologists. AGA American Gastroenterological Association; BSG British Society for Gastroenterology; CCA Canadian Celiac Association; NASPGHAN North American Society for Pediatric Gastroenterology, Hepatology and Nutrition; NIH National Institutes of Health; PCSG Primary Care Society for Gastroenterology; WGO World Gastroenterology Organisation

always performed follow-up serological tests (tissue transglutaminase [tTG] antibody, antigliadin antibody or endomysial antibody [EMA]). In contrast to follow-up duodenal biopsy, pediatric gastroenterologists almost always perform follow-up serology more often than their adult counterparts ( $86 \%$ versus $48 \% ; \mathrm{P}<0.01$ ). Of the remainder, $29 \%$ almost never performed follow-up serology. Those who did not provide routine long-term follow-up care were significantly more likely to almost never perform follow-up serology ( $57 \%$ versus $20 \%$; $\mathrm{P}<0.01$ ). 
TABLE 3

Comparison of respondents who provided and did not provide long-term follow-up to patients with celiac disease

\begin{tabular}{|c|c|c|c|c|c|c|}
\hline & \multicolumn{2}{|c|}{ Gastroenterologists } & \multirow[b]{2}{*}{$\mathbf{P}^{\dagger}$} & \multicolumn{2}{|c|}{ Gastroenterologists who follow-up } & \multirow[b]{2}{*}{$\mathbf{P}^{\ddagger}$} \\
\hline & Who do not follow-up (n=49) & Who follow-up $(n=181)^{*}$ & & Adult $(n=138)$ & Pediatric $(n=42)$ & \\
\hline Practice type & & & 0.08 & & & $<0.01$ \\
\hline Academic & $19(39)$ & $100(55)$ & & $64(46)$ & $35(83)$ & \\
\hline Private & $17(35)$ & $53(29)$ & & $49(36)$ & $4(10)$ & \\
\hline Mixed & $13(26)$ & $28(16)$ & & $25(18)$ & $3(7)$ & \\
\hline Location & & & $<0.05$ & & & 0.14 \\
\hline East & $8(16)$ & $17(9)$ & & $13(10)$ & $4(10)$ & \\
\hline Years in practice & & & 0.15 & & & $<0.05$ \\
\hline $0-10$ & $14(29)$ & $75(41)$ & & $51(37)$ & $24(57)$ & \\
\hline $11-20$ & $13(27)$ & $52(29)$ & & $40(29)$ & $12(29)$ & \\
\hline $21-30$ & $11(22)$ & $33(18)$ & & $27(20)$ & $5(12)$ & \\
\hline $101-200$ & $6(12)$ & $6(3)$ & & $2(1)$ & $4(10)$ & \\
\hline$>200$ & $1(2)$ & $4(2)$ & & $2(1)$ & $2(5)$ & \\
\hline No answer & $4(8)$ & $2(1)$ & & $1(0)$ & $1(2)$ & \\
\hline \multicolumn{7}{|l|}{ Information sources } \\
\hline Conferences & $26(53)$ & $160(88)$ & $<0.01$ & $118(86)$ & 41 (98) & $<0.05$ \\
\hline Colleagues & $24(49)$ & $96(53)$ & 0.61 & $69(50)$ & $26(62)$ & 0.18 \\
\hline Practice guidelines & $24(49)$ & $129(71)$ & $<0.01$ & $92(67)$ & $36(86)$ & $<0.05$ \\
\hline Medical journals & $37(76)$ & $144(80)$ & 0.54 & $111(80)$ & $32(76)$ & 0.55 \\
\hline Canadian Celiac Association & $10(20)$ & $50(28)$ & 0.31 & $37(27)$ & $12(29)$ & 0.82 \\
\hline Other celiac associations & $2(4)$ & $14(8)$ & 0.37 & $9(7)$ & $1(2)$ & 0.51 \\
\hline \multicolumn{7}{|l|}{ Practice guideline familiarity } \\
\hline
\end{tabular}

Data presented as $n$ (\%) unless indicated otherwise. *Includes one respondent with a mixed practice of 60:40 who could not be classified as either an adult or pediatric gastroenterologist; ${ }^{\dagger}$ Comparison between all gastroenterologists who provided long-term follow-up with those who did not follow patients with celiac disease. ${ }^{\ddagger}$ Comparison between adult and pediatric gastroenterologists who provided follow-up to patients with celiac disease. AGA American Gastroenterological Association; BSG British Society for Gastroenterology; NASPGHAN North American Society for Pediatric Gastroenterology, Hepatology and Nutrition; NIH National Institutes of Health; PCSG Primary Care Society for Gastroenterology; WGO World Gastroenterology Organisation

The timing of follow-up serology varied depending on how frequently the respondent reported performing the test. Those who perform routine follow-up serology 'almost always' tended to test early, with $16 \%$ first testing at three months, $57 \%$ at six months and 26\% first testing at one year. Those who did not perform follow-up serology routinely tested later, with $47.4 \%$ waiting six months after initiation of a gluten-free diet and $42.1 \%$ waiting one year. The remaining $10.5 \%$ reported that their practices were highly variable or that they waited nine months. These rates did not vary significantly with practice demographics or between subgroups, including pediatric and adult gastroenterologists, and those who almost always provided follow-up care versus those who did not.

Long-term follow-up care

Participants were asked to indicate either the frequency of routine long-term follow-up or reasons for not providing routine follow-up. Three-quarters of respondents reported providing routine long-term follow-up care to patients with celiac disease. There were seven respondents who indicated both their long-term follow-up practices and reasons for not providing long-term follow-up. These responses were not included in the analysis of long-term follow-up practices because they could not be accurately categorized. There was no significant difference in the proportion of adult $(75 \%)$ and pediatric $(82 \%)$ gastroenterologists who provided routine long-term follow-up care.

Provision of long-term follow-up care was not significantly associated with practice type or the number of patients with celiac disease in a practice. The characteristics of gastroenterologists who did and did not provide routine follow-up to patients with celiac disease are compared in Table 3. Gastroenterologists in Central Canada were significantly more likely to provide long-term follow-up (86\% versus $71 \%$ in the West, and $68 \%$ in the Atlantic regions; $\mathrm{P}<0.05)$. 
Gastroenterologists who did not routinely provide longterm follow-up to patients diagnosed with celiac disease tended to have a mixed rather than an academic practice and to have been in practice for longer than those who routinely provide long-term follow-up. They were significantly less likely to use conferences $(53 \%$ versus $88 \%$; $\mathrm{P}<0.01)$ or practice guidelines (49\% versus $71 \% ; \mathrm{P}<0.01)$ for information. There was a trend toward increased levels of unfamiliarity with any practice guidelines ( $18 \%$ versus $9 \% ; \mathrm{P}=0.08)$. The most commonly cited reason for not providing long-term follow-up was that the patient's primary care physician provided this care $(86 \%)$. Other reasons cited included not having an organized system to recall patients (39\%) and lack of time (33\%). Many indicated that, in their view, follow-up is not required once the patient is on a glutenfree diet $(20 \%)$ or that patients do not want follow-up (12\%).

\section{Long-term follow-up: Who should be involved?}

Participants were asked to indicate who they believe should be involved in long-term follow-up care of patients with celiac disease (Table 4). Gastroenterologists with celiac disease patients in their practices were divided on whether care should be provided by a specialist gastroenterologist $(54 \%)$ or by a family physician (59\%). These numbers sum to greater than $100 \%$ because some respondents believe that care should be provided by both health care providers. The $6 \%$ who selected 'other' expressed the opinion that the discipline and title of the individual providing long-term follow-up is less important than interest and knowledge, and that the key element is access to a gastroenterologist or an endoscopist if indicated. Consistent with their reported practices, $92 \%$ of those who did not routinely provide long-term follow-up believed that this care should be provided by a primary care physician, and $67 \%$ of those who provide long-term follow-up care believed that gastroenterologists should fulfill this role.

Compared with adult gastroenterologists, pediatric gastroenterologists believed more strongly that care should be provided by a specialist gastroenterologist $(\mathrm{P}<0.05)$ or internist/ pediatrician $(\mathrm{P}<0.01)$, and were significantly less likely to believe that care should be provided by family physicians (OR $0.291 ; 95 \%$ CI 0.152 to 0.557 ; $<<0.01$ ). When only those who provided long-term follow-up care to their own patients were considered, there was no significant difference between adult and pediatric gastroenterologists regarding whether gastroenterologists should be involved in providing long-term follow-up; however, the differences regarding involvement of internists/ pediatricians and family doctors remained significant.

\section{Long-term follow-up: Who is involved?}

Gastroenterologists who reported that they provide long-term follow-up care routinely to their patients with celiac disease were asked who was involved in providing this care. Overall, three-quarters of participants indicated that the patient's primary care physician and specialist gastroenterologist were always involved and one-half always involved a dietitian. Only $1 \%$ always involved a psychologist. One individual reported involving members of the local celiac association in follow-up.

Pediatric follow-up was generally more multidisciplinary, with 29\% almost always involving a nurse (versus 2\% of adult gastroenterologists; OR 18; 95\% CI 4.8 to 68 ; P<0.01) and $81 \%$ almost always involving a dietitian (versus $43 \%$ of adult gastroenterologists; OR 5.8; 95\% CI 2.5 to 13; P<0.01). Pediatric
TABLE 4

Who should follow patients with celiac disease?

\begin{tabular}{|c|c|c|c|c|c|}
\hline & $\mathbf{n}$ & $\begin{array}{c}\text { Specialist } \\
\text { gastroenterologist }\end{array}$ & $\begin{array}{c}\text { Internist/ } \\
\text { pediatrician }\end{array}$ & $\begin{array}{l}\text { Family } \\
\text { physician }\end{array}$ & Other \\
\hline $\begin{array}{l}\text { All with patients with } \\
\text { celiac disease }\end{array}$ & 237 & 54 & 15 & 59 & 6 \\
\hline $\begin{array}{l}\text { All who follow } \\
\text { patients with } \\
\text { celiac disease }\end{array}$ & 181 & 67 & 18 & 49 & 6 \\
\hline All who do not follow & 49 & 12 & 4 & 92 & 2 \\
\hline All adult & 184 & 51 & 9 & 65 & 3 \\
\hline All pediatric & 51 & 69 & 33 & 35 & 5 \\
\hline Adult who follow & 138 & 64 & 12 & 56 & 4 \\
\hline $\begin{array}{l}\text { Pediatric who } \\
\text { follow }\end{array}$ & 42 & 79 & 33 & 26 & 12 \\
\hline
\end{tabular}

Data presented as \% unless indicated otherwise. Rows do not sum to $100 \%$ because respondents were allowed to select more than one option

gastroenterologists were less likely to involve the primary care physician (55\% versus 70\%; OR 0.322; 95\% CI 0.155 to 0.670 ; $\mathrm{P}<0.01)$. These differences were independent of practice type.

The role of specific team members was not elicited; however, gastroenterologists were asked who reviewed the glutenfree diet with patients if they were followed. More than three-quarters involved a dietitian and this did not vary appreciably between adult and pediatric practitioners, or between those who did and did not provide long-term follow-up. The highest rate $(81 \%)$ was reported among pediatric gastroenterologists who provided long-term follow-up, and the lowest rate (76.1\%) was among adult gastroenterologists who provided long-term follow-up. The rate of gastroenterologist participation in diet review was much more variable. The overall rate was $44.9 \%$ and did not vary significantly between adult and pediatric practitioners. Nearly one-half of those who provided long-term follow-up reviewed the diet with their patients. The lowest rate of gastroenterologist involvement in dietary review (30.2\%) was among adult gastroenterologists who did not provide long-term follow-up.

Gastroenterologists with a primarily academic practice were significantly more likely to involve a gastroenterologist in follow-up care (83\% versus 62\%; OR 2.9; 95\% CI 1.4 to 6.3 ; $\mathrm{P}<0.01)$. None of the private practices involved a nurse. There was no statistically significant association between practice type and involvement of dietitians in follow-up care. The rate of involvement of primary care physicians varied significantly across regions ( $82 \%$ West, 65\% Central and 94\% East; $\mathrm{P}<0.01$ ), but the involvement of other team members did not.

\section{Long-term follow-up: What is involved?}

Most gastroenterologists (67\%) provided long-term follow-up care in the form of an annual clinic visit, whereas 19\% provided care during the first year only. Several respondents indicated that they provided more frequent follow-up in the years following the diagnosis. Most (72\%) provided similar follow-up to patients with silent celiac disease. A single approach to symptomatic and asymptomatic patients was significantly more common among pediatric (86\%) than adult (67\%) gastroenterologists (OR 2.9; 95\% CI 1.1 to 7.4 ).

The details of provision of various elements of longterm follow-up are summarized in Table 5. The majority of 


\begin{tabular}{|c|c|c|c|c|c|}
\hline & \multicolumn{3}{|c|}{ Gastroenterologists who follow-up } & \multirow[b]{2}{*}{$\mathbf{P}^{\dagger}$} & \multirow[b]{2}{*}{ OR $(95 \% \mathrm{Cl})$} \\
\hline & All $(n=181)^{*}$ & Adult $(n=138)$ & Pediatric $(n=42)$ & & \\
\hline \multicolumn{6}{|l|}{ Disease status evaluation } \\
\hline Measure weight and height & $131(72)$ & $88(64)$ & $42(100)$ & $<0.001$ & Not calculable \\
\hline Calculate body mass index & $69(38)$ & $43(31)$ & $26(62)$ & $<0.01$ & $0.28(0.14-0.57)$ \\
\hline Physical examination & $141(78)$ & $99(72)$ & $41(98)$ & $<0.01$ & $0.064(0.009-0.483)$ \\
\hline \multicolumn{6}{|l|}{ Laboratory investigations } \\
\hline Folate & $72(40)$ & $64(46)$ & $7(17)$ & $<0.01$ & $4.3(1.8-10)$ \\
\hline Ferritin & $117(65)$ & $97(70)$ & $20(48)$ & $<0.01$ & $2.6(1.3-5.3)$ \\
\hline Vitamin $B_{12}$ & $54(30)$ & $49(36)$ & $5(12)$ & $<0.01$ & $4.1(1.5-11)$ \\
\hline Albumin & $116(64)$ & $87(63)$ & $29(69)$ & 0.48 & \\
\hline Electrolytes & $61(34)$ & $58(42)$ & $3(7)$ & $<0.01$ & $9.4(2.8-32)$ \\
\hline Calcium & $90(50)$ & $79(57)$ & $11(26)$ & $<0.01$ & $3.8(1.8-10)$ \\
\hline Vitamin D & $38(21)$ & $29(21)$ & $9(21)$ & 0.95 & \\
\hline Parathyroid hormone & $8(4)$ & $6(4)$ & $2(5)$ & 0.90 & \\
\hline Vitamin A & $21(12)$ & $14(10)$ & $7(17)$ & 0.25 & \\
\hline Vitamin E & $13(7)$ & $6(4)$ & $7(17)$ & $<0.01$ & $0.23(0.072-0.72)$ \\
\hline Thyroid-stimulating hormone & $72(40)$ & $50(36)$ & $21(50)$ & 0.11 & \\
\hline \multicolumn{6}{|l|}{ Radiological investigations } \\
\hline Dual energy x-ray absorptiometry scanning & $94(52)$ & $85(62)$ & $8(19)$ & $<0.01$ & $6.8(2.9-16)$ \\
\hline \multicolumn{6}{|l|}{ Self-management support } \\
\hline Dietary review & $138(76)$ & $101(74)$ & $36(86)$ & 0.11 & \\
\hline
\end{tabular}

${ }^{*}$ Includes one respondent with a mixed practice of 60:40 who could not be classified as either an adult or pediatric gastroenterologist; ${ }^{\dagger}$ Comparison between adult and pediatric gastroenterologists who provided long-term follow-up

gastroenterologists surveyed almost always measured the patient's weight and height (72\%), and performed a physical examination (78\%). The patient's diet was reviewed $(76 \%)$, the need for adherence was reinforced (90\%) and membership in an advocacy group was recommended (65\%).

Investigations commonly requested included serology (65\%), a hemoglobin level or complete blood count $(83 \%)$, ferritin $(65 \%)$, albumin (64\%), calcium (50\%), liver transaminases (60\%) and alkaline phosphatase (51\%). A dualenergy $\mathrm{x}$-ray absorptiometry (DEXA) scan was almost always included in follow-up by $52 \%$ of respondents. Of the 48 individuals who used EMA and/or antigliadin antibody serology in long-term follow-up, 47 used tTG as often or more often than EMA/antigliadin antibody; therefore, serology in the present article refers to tTG.

When comparing the responses of the two types of gastroenterologists, pediatric specialists were significantly more likely to measure patient weight and height $(\mathrm{P}<0.001)$. The adult gastroenterologists were much less likely than pediatric gastroenterologists to measure body mass index and perform a physical examination (Table 5). As with the entire population of gastroenterologists, adult gastroenterologists who follow their celiac disease patients were much less likely to follow serology (OR 0.28; 95\% CI 0.12 to 0.69). Adult gastroenterologists were more likely to follow folate (OR 4.3; 95\% CI 1.8 to 10 ), ferritin (OR 2.6; 95\% CI 1.3 to 5.3) and calcium levels (OR 3.8; 95\% CI 1.8 to 8.1 ) and to order DEXA scans (OR $6.8 ; 95 \%$ CI 2.9 to 16$)$.

Participants were given the option of indicating whether they included follow-up investigations as part of long-term follow-up of patients with celiac disease 'almost always', 'only if previously abnormal', 'if symptoms recur' or 'almost never'. Many respondents almost never monitor vitamin A (33\%), $\mathrm{B}_{12}$ (18\%), D (28\%) and E (41\%) levels. Parathyroid hormone and thyroid-stimulating hormone levels were almost never tracked by $39 \%$ and $17 \%$ of respondents, respectively. Serology was almost never repeated in follow-up by $8.8 \%$ of respondents. Divergence between adult and pediatric practices was most evident for DEXA scanning, which $62 \%$ of adult gastroenterologists almost always included compared with $19 \%$ of pediatric gastroenterologists. Nearly one-half (45\%) of pediatric gastroenterologists almost never ordered DEXA scans during follow-up. Similarly, calcium levels were almost always monitored by $57 \%$ of adult gastroenterologists and almost never by $26 \%$ of pediatric gastroenterologists.

\section{DISCUSSION}

To our knowledge, the present study is the first to investigate the practices of gastroenterologists regarding long-term follow-up of patients with celiac disease and to determine the extent to 
which guidelines for follow-up are applied in clinical practice. Thus, the current study attempted to capture not only the logistics of follow-up regarding whether to provide care, by whom and how often, but also the content of follow-up. In addition to determining what is done, we were interested in what respondents believed ought to be done.

The goal was to survey the entire community of gastroenterologists actively practicing in Canada. The actual number is not known because there is no central agency in Canada responsible for tracking specialist physicians. Directory searches produced a listing of 585 physicians, which was subsequently reduced to 567 because some addresses were undeliverable while some physicians reported that they were not actively practicing. We are confident that almost all gastroenterologists were included in the study because this estimate was consistent with a Canadian Association of Gastroenterology report of 550 practicing gastroenterologists in 2005 (13).

Although the distribution of surveys and, hence, gastroenterologists, was reflective of the distribution of the Canadian population in the 2006 census, differences in regional response rates resulted in an over-representation of Atlantic Canada (the least populous region) and an under-representation of central Canada (the most populous region). The cause of the difference in response rates was not clear.

\section{To follow or not to follow?}

Seventy-six per cent of the gastroenterologists who responded indicated that they provided long-term follow-up care to their patients diagnosed with celiac disease. This cannot be equated with a similar proportion of patients with celiac disease receiving long-term follow-up care by a specialist gastroenterologist. Reasons for this include a possible selection bias favouring respondents who provided long-term follow-up as well as attrition of patients over time and/or during transition from pediatric to adult care. One limitation of the current study is that it considered only what gastroenterologists viewed of their practices, and did not elicit the opinions of allied health professionals or patients. Another reason for patients not receiving follow-up is that in Canada (14), as elsewhere (15), not all patients with a positive serological test are referred for biopsy. The reported follow-up rate of $76 \%$ is higher than the $57 \%$ of patients from a duodenal biopsy database in the United Kingdom (UK) who reported receiving specialist physician follow-up a mean of 5.4 years after biopsy (16). A similar proportion of Celiac UK members in Eastern Scotland reported not receiving any follow-up care for their celiac disease (Dr G Mahdi, personal communication).

Of the gastroenterologists who did not provide long-term follow-up, 20\% of Canadian gastroenterologists indicated that follow-up is not needed if the patient is on a gluten-free diet. Interestingly, those who did not provide follow-up were also significantly less likely to personally review the diet with the patient, which suggests that they may be less familiar with the challenges involved in maintaining a strict gluten-free diet. All reasons given for not providing long-term follow-up are summarized in Figure 1. There were 12\% who reported not providing long-term follow-up because their patients did not want it. The only evidence on this topic other than anecdotal reports comes from a survey of patients in the UK (16) in which "no follow-up" was the least preferred among five options, even among those

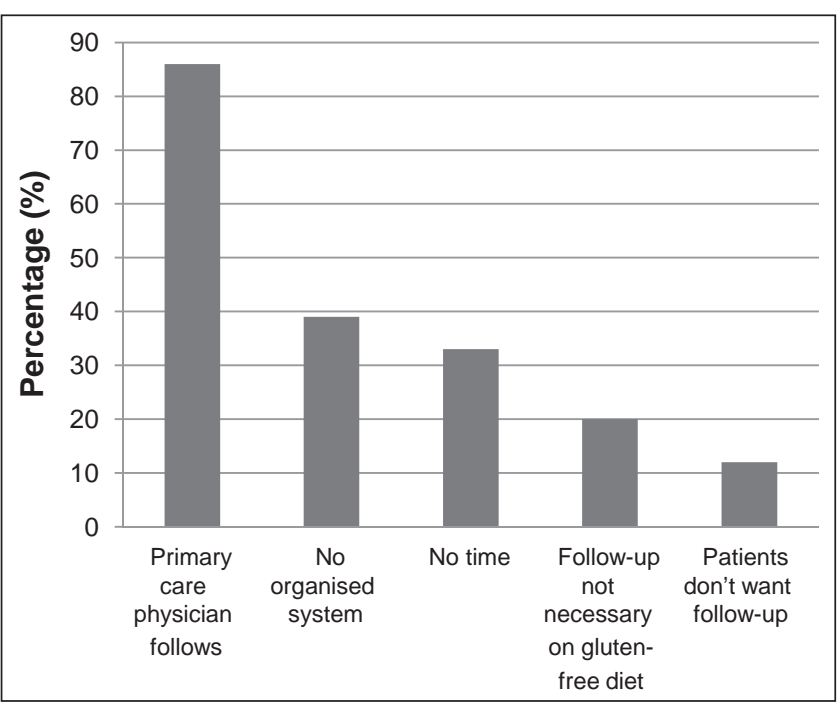

Figure 1) Reasons cited by gastroenterologists for not providing longterm follow-up care to patients with celiac disease

who had been diagnosed for more than five years. Follow-up with the patient's general practitioner was the second-least preferred option. In contrast, the number one reason given by gastroenterologists in our study for not providing long-term follow-up was that the family physician fulfilled this role.

\section{Who is involved in long-term management?}

The notion that patients with celiac disease should be monitored for life by a team of health care professionals is advocated to varying extents by all the current practice guidelines. Gastroenterologists in Canada recognize a prominent role for other health care providers to be involved regardless of whether they do so themselves. Notably, $86 \%$ of those who did not provide long-term follow-up care stated that the primary care physician did so, and that $74 \%$ of those who did provide longterm follow-up stated that the primary care physician was also involved in providing follow-up. There is clearly an expectation that primary care physicians are providing follow-up care to their patients diagnosed with celiac disease; however, there are no data available to confirm this. Also, how often primary care physicians identify themselves as fulfilling this role remains unknown. It is also not clear whether patients perceive family physicians to be providing adequate long-term follow-up. In a survey of patients with celiac disease conducted in the UK (16), only $62 \%$ reported receiving follow-up for their condition, yet $89 \%$ were receiving prescriptions for gluten-free products (16). Only $5 \%$ of respondents indicated that they were receiving follow-up from their general practitioner. Although celiac disease is relatively common, it is often unrecognized and many primary care physicians are not familiar with symptoms of this disorder in adults (17). Relatively little is known about primary care physicians' knowledge of long-term management and complications of celiac disease.

There was less agreement about who ought to follow patients with celiac disease. Those who provided long-term follow-up care themselves were less inclined to recognize a role for the primary care physician, with pediatricians particularly hesitant to involve a generalist, preferring pediatric follow-up instead. A possible reason for this is that, in many provinces in Canada, 
family physicians have only recently become responsible for providing primary care for children, and this role has traditionally been the mandate of the generalist pediatrician. Also, measurement of growth patterns is an integral part of pediatric, but not adult practice. Pediatricians may view themselves as more suited to monitor the growth of a child with celiac disease.

There was a strong sentiment that particular professional qualifications are less important than disease-specific knowledge in determining who should provide follow-up care. This suggests that there may be general acceptance of nontraditional management models in which patients with celiac disease are followed in dietitian- or nurse practitioner-led clinics. One respondent reported having implemented the latter strategy in a large practice with more than 200 patients diagnosed with celiac disease. Another practice included volunteers from the local chapter of the national celiac association in follow-up to assist with diet review because they "know more than the dietitian and me". There is a single study (16) reporting a patient preference for dietitian follow-up with a physician available. In contrast, in its 2001 medical position statement (9), the AGA concluded that "it is wise, therefore, that follow-up should be undertaken by a physician".

In Canada, the involvement of multiple health care professionals in the follow-up of patients with celiac disease is being realized to a much greater extent in pediatric than in adult clinics. The specific roles of different team members were not evaluated in the present survey; however, there was some indication that dietitians were involved in short-term but not in long-term follow-up. Specifically, 78\% involved a dietitian in diet review, but this was not always sustained because only $43 \%$ of adult gastroenterologists reported almost always involving a dietitian in long-term follow-up. One might assume that this negatively affects the quality of patient assessment and care provided because dietitians often receive more training than physicians regarding gluten-free diets. However, there is limited evidence regarding the effect of dietary review with a dietitian on compliance, quality of life or health outcomes. In a national survey (12) of members of the CCA, the quality of information provided by dietitians and physicians was rated as fair or poor by nearly one-quarter of respondents with celiac disease. The CCA or a local chapter were rated as excellent sources twice as often as dietitians or gastroenterologists. In the same study, only $13 \%$ identified better dietary counselling as something that would improve their quality of life. In contrast, nearly $60 \%$ of patients in a UK study (16) rated the opportunity for dietary review and to ask questions about the diet to be a useful or very useful aspect of follow-up. Although it is intuitive that involvement of dietitians would strengthen the team, more research is needed to define their role to optimize their contribution to maximize the use of this resource.

\section{What to follow?}

The current practice guidelines for the management of celiac disease vary considerably with respect to the details of longterm follow-up; however, they are all clear that the only effective treatment available is lifelong adherence to a strict gluten-free diet. With this in mind, some of the observed variability in the content of long-term follow-up care is expected, such as the higher reported rate of recording weight and height and calculating body mass index during follow-up visits by pediatric gastroenterologists. However, it is quite surprising that $10 \%$ of gastroenterologists who participated in the current study did not almost always reinforce the need to adhere to a gluten-free diet. There is no obvious explanation for why all of the gastroenterologists who did not routinely reinforce the need for adherence to a gluten-free diet primarily treated adults. While one can not discount the possibility that these gastroenterologists were generally confident that their patients were already following a strict gluten-free diet, it is, nevertheless, surprising that the need for compliance is not reinforced routinely by all.

The follow-up elements recommended by various practice guidelines and experts are compared with the reported practices of gastroenterologists in the present study in Table 6. The reported practices do not clearly correspond with any particular practice guideline. Nevertheless, some of the observed differences between pediatric and adult practices may be accounted for by differences between the NASPGHAN and the 2001 AGA guidelines. Specifically, the NASPGHAN guidelines recommend physical examination and follow-up serology, while the AGA guidelines do not. The NASPGHAN guidelines do not recommend any additional laboratory tests be performed routinely, whereas the AGA guidelines recommend monitoring hemoglobin, folate, ferritin, calcium and alkaline phosphatase levels. With the exception of folate, the majority of adult gastroenterologists are performing these tests.

In a revised medical position statement released in late 2006 (4), the AGA advocated monitoring serology only for children and adults without the additional tests listed above. Our survey was conducted in early 2008, approximately one year after the revised AGA guidelines were published; thus, it is possible that the new guidelines had not yet been adopted by most practitioners. The expert opinion of Haines et al (18) was published later in 2008, after the survey was completed, and is provided for comparison purposes only.

Notably, there are several other tests that are routinely included, which are supported only on the basis of expert opinion. These include albumin and liver transaminases, which are monitored routinely by more than $60 \%$ of gastroenterologists providing long-term follow-up care to patients with celiac disease. A significant number (40\%) also routinely screen for hypothyroidism with thyroid-stimulating hormone level even though this practice is not endorsed by any of the guidelines. The expert recommendation of Haines et al (18) to screen annually for hypothyroidism was made after the survey was conducted, and is based on the relatively low cost and simple nature of the test in the absence of any evidence demonstrating that asymptomatic patients with celiac disease would benefit from screening for hypothyroidism.

\section{To biopsy or not to biopsy in follow-up?}

Although characteristic changes in the histology of the small intestinal mucosa remain the gold standard for the diagnosis of celiac disease, recommendations for follow-up or repeat duodenal biopsy have become less stringent over time $(19,20)$. It is now generally agreed that a single biopsy and resolution of symptoms on a gluten-free diet is adequate for diagnosis, although the AGA did not endorse this practice until 2006 $(4,6)$. This likely explains the five-fold higher rate of routine repeat biopsy among adult gastroenterologists. In fact, several adult gastroenterologists specifically indicated that they were changing their practices and performing fewer repeat biopsies. 


\begin{tabular}{|c|c|c|c|c|c|c|c|c|c|c|}
\hline & \multicolumn{7}{|c|}{ Guidelines/recommendations, year (reference) } & \multicolumn{3}{|c|}{$\begin{array}{c}\text { Gastroenterologists who } \\
\text { follow-up, } \%\end{array}$} \\
\hline & $\begin{array}{c}\text { AGA, } \\
2001 \\
(9) \\
\end{array}$ & $\begin{array}{c}\text { AGA, } \\
2006 \\
(4) \\
\end{array}$ & $\begin{array}{c}\text { NIH, } \\
2004 \\
(7) \\
\end{array}$ & $\begin{array}{c}\text { NASPGHAN, } \\
2005 \\
(6) \\
\end{array}$ & $\begin{array}{c}\text { PCSG, } \\
2006 \\
(27)\end{array}$ & $\begin{array}{c}\text { Pietzak, } \\
2005 \\
(28)\end{array}$ & $\begin{array}{c}\text { Haines } \\
\text { et al, } 2008 \\
(18)\end{array}$ & All $(n=181)^{*}$ & $\begin{array}{c}\text { Adult } \\
(n=138)\end{array}$ & $\begin{array}{c}\text { Pediatric } \\
(n=42)\end{array}$ \\
\hline \multicolumn{11}{|l|}{ Disease status evaluation } \\
\hline Assess symptoms by interview & $\checkmark$ & $\checkmark$ & $\checkmark$ & $\checkmark$ & $\checkmark$ & $\checkmark$ & $\checkmark$ & N/A & N/A & N/A \\
\hline Measure weight, and height & $\checkmark$ & & & $\checkmark$ & $\checkmark$ & $\checkmark$ & & 76 & 64 & 100 \\
\hline Calculate body mass index & & & & & & & & & & 62 \\
\hline Physical examination & & & & $\checkmark$ & & $\checkmark$ & & 72 & 72 & 98 \\
\hline \multicolumn{11}{|l|}{ Laboratory investigations } \\
\hline Serology & & $\checkmark$ & $\checkmark$ & $\checkmark$ & $\checkmark$ & $\checkmark$ & $\checkmark$ & 64 & 59 & 83 \\
\hline Albumin & & & & & $\checkmark$ & $\checkmark$ & $\checkmark$ & 64 & 63 & 69 \\
\hline Hemoglobin or complete blood count & $\checkmark$ & & & & $\checkmark$ & $\checkmark$ & $\checkmark$ & 83 & 86 & 76 \\
\hline Folate & $\checkmark$ & & & & $\checkmark$ & $\checkmark$ & $\checkmark$ & & & \\
\hline Ferritin & $\checkmark$ & & & & $\checkmark$ & $\checkmark$ & $\checkmark$ & 65 & 70 & \\
\hline Vitamin $\mathrm{B}_{12}$ & & & & & $\checkmark$ & & $\checkmark$ & & & \\
\hline Liver transaminases & & & & & & $\checkmark$ & & 60 & 62 & \\
\hline Alkaline phosphatase & $\checkmark$ & & & & $\checkmark$ & $\checkmark$ & & 51 & 56 & \\
\hline Calcium & $\checkmark$ & & & & $\checkmark$ & $\checkmark$ & $\checkmark$ & 50 & 57 & \\
\hline Vitamin D & & & & & $\checkmark$ & $\checkmark$ & $\checkmark$ & & & \\
\hline Phosphate & & & & & & & $\checkmark$ & & & \\
\hline Parathyroid hormone & & & & & & $\checkmark$ & & & & \\
\hline Prothrombin time & & & & & & $\checkmark$ & $\checkmark$ & & & \\
\hline Vitamins $A$ and $E$ & & & & & & $\checkmark$ & & & & \\
\hline Electrolytes & & & & & & $\checkmark$ & $\checkmark$ & & & \\
\hline Thyroid function & & & & & & & $\checkmark$ & & & \\
\hline Fasting glucose & & & & & & & $\checkmark$ & & & \\
\hline \multicolumn{11}{|l|}{ Radiological investigations } \\
\hline Dual energy x-ray absorptiometry scan & & & & & $\checkmark$ & $\checkmark$ & & 52 & 62 & \\
\hline \multicolumn{11}{|l|}{ Self-management support } \\
\hline Dietary review with a dietitian ${ }^{\dagger}$ & & $\checkmark$ & $\checkmark$ & $\checkmark$ & $\checkmark$ & $\checkmark$ & $\checkmark$ & 78 & 73 & 86 \\
\hline Reinforce need for adherence to a GFD & $\checkmark$ & $\checkmark$ & & $\checkmark$ & $\checkmark$ & & $\checkmark$ & 90 & 87 & 100 \\
\hline Recommend advocacy group membership & $\checkmark$ & $\checkmark$ & $\checkmark$ & $\checkmark$ & $\checkmark$ & $\checkmark$ & & 64 & 62 & 74 \\
\hline
\end{tabular}

Check marks indicate that a practice guideline or experts recommend a given practice. Percentages are given when greater than $50 \%$ of individuals in a category indicated that they 'almost always' followed a particular practice. *Includes one respondent with a mixed practice of 60:40 who could not be classified as either an adult or pediatric gastroenterologist; ${ }^{\dagger}$ For respondents, refers only to dietary review, which may not be performed by a dietician. AGA American Gastroenterological Association; GFD Gluten-free diet; NASPGHAN North American Society for Pediatric Gastroenterology, Hepatology and Nutrition; N/A Not available; NIH National Institutes of Health; PCSG Primary Care Society for Gastroenterology

One consequence of ending repeat duodenal biopsy as standard practice is that the indications for repeat biopsy need to be defined. In the present study, the most common indication for routine or early repeat duodenal biopsy during follow-up was ongoing symptoms despite patients claiming to be on a gluten-free diet. Many gastroenterologists are also routinely performing repeat biopsies on patients who are immunoglobulin A-deficient or have histological changes but are tTG negative. Another indication is persistently abnormal blood work after six or more months on a gluten-free diet. During longer term follow-up, the underlying reason for repeat biopsy is most often concern that changes in symptoms or laboratory values may reflect development of a $T$ cell lymphoma. Current practice guidelines do not offer any specific guidance regarding who should receive a repeat biopsy routinely; however, they are clear that ongoing or new symptoms are an indication for repeat biopsy.

What is the role of patient advocacy groups?

The delivery of health care is shifting from an acute care model to a chronic disease model, in part, because "patients self-manage their illness. This fact is inescapable. Each day, patients decide what they are going to eat, whether they are going to exercise and to what extent they will consume prescribed medications" (21). One strength of the guidelines for management of celiac disease is their implicit recognition of this fact, which is expressed through the recommendation that physicians advise patients with celiac disease to join a patient advocacy group. In Canada, the CCA fulfills this role with a national office and 28 local chapters.

The relationship between the CCA and gastroenterologists is bidirectional. Nearly one-third of gastroenterologists reported that they used the CCA as a source of information about celiac disease and nearly two-thirds almost always recommended that patients join an advocacy group during long-term follow-up. One gastroenterologist even involved group members in long-term follow-up because of their expertise in adhering to the diet. Gastroenterologists who reported using the CCA as a source of information were significantly less likely to provide follow-up themselves $(71 \%$ versus $85 \% ; \mathrm{P}<0.05)$. Interestingly, those who routinely recommended advocacy 
group membership were less likely to almost always perform routine repeat intestinal biopsy ( $34 \%$ versus $54 \% ; \mathrm{P}<0.05$ ) and more likely to reinforce the need for adherence to a gluten-free $\operatorname{diet}(95 \%$ versus $83 \% ; \mathrm{P}<0.01)$. There was no significant difference in the extent of laboratory monitoring performed by gastroenterologists who provided follow-up themselves.

The present study did not capture patient experiences with follow-up; consequently, one can only speculate whether gastroenterologists preferred more or less involvement with support groups and what their preferred form and means of follow-up would be. Nevertheless, both physicians and individuals with celiac disease have identified the CCA as an important resource (12).

Ironically, the 'self-management support' component of celiac disease care is arguably one of the more critical pieces, but also the area in which health care providers are less able to assist the patient. One successful approach that acknowledges these limitations is the Expert Patients Program (22) in the UK, in which individuals learn how to cope with the challenges of a chronic condition from each other. Many elements of this program are similar to work already being performed by celiac patient support groups. More research is needed to develop models of care that transcend the boundaries of the clinic and the health care system to involve and empower those with celiac disease in their daily lives.

What is the impact of follow-up for the health care system? The true prevalence of celiac disease in Canada is unknown; however, there is general consensus that the individuals currently diagnosed represent the tip of the iceberg because most individuals with celiac disease have not been diagnosed (23). Prevalence estimates are that approximately $1 \%$ of the North American population has celiac disease, which corresponds to approximately 300,000 Canadians. Thus, one factor that must be considered in determining who, how and what to monitor for patients with celiac disease is the benefit versus burden on the health care system.

The cost per patient of performing tTG serology is only $\$ 17.44$ per year (completed once). The tests that are 'almost always' ordered by most pediatric gastroenterologists (serology, complete blood count and albumin) would cost $\$ 27.59$ per patient per year. The additional tests 'almost always' ordered by most adult gastroenterologists (calcium, ferritin and liver enzymes) would cost another $\$ 34.35$ per patient per year. This does not include the cost of DEXA scanning, consultation with a physician or consultation with a dietician. Notably, Canadian gastroenterologists are recommending only a subset of the tests recommended by experts. The cost of tests recommended by Haines et al (18) is $\$ 151.13$ per patient per year. (Reference values for the cost of laboratory tests were provided by the Department of Laboratory Medicine at the IWK Health Centre, Dalhousie University, Halifax, Nova Scotia.)

The above estimates include only the laboratory cost of testing and do not include the associated costs for administering the test, or reviewing and communicating results. They also do not include the cost of additional testing or interventions (eg, repeat endoscopy) prompted by the results of these tests. While these costs can be enormous, the benefits are less clear. There is minimal information regarding the intermediate and long-term recovery of nutritional and laboratory markers on a gluten-free diet, although they do tend to normalize within months to years of introduction of a strict gluten-free diet in both children and adults (24-26). It is unknown how many individuals with significant complications would not be detected even with a high level of testing. Nor is it known whether asymptomatic individuals will receive the same benefit as those who present with overt symptoms.

\section{CONCLUSION}

Most gastroenterologists in Canada provide routine long-term follow-up to their patients with celiac disease. Those who do not are delegating this role to the patient's primary care physician. Follow-up is most often provided on an annual basis, and includes reinforcement of the need to adhere to a gluten-free diet, dietary review, physical examination, laboratory tests and a recommendation to join a patient support and advocacy group. Performance of investigations, including routine laboratory tests, nutritional screening, serology, bone health screening and follow-up biopsy vary considerably among gastroenterologists. There is a need to develop consensus and evidence-based guidelines for follow-up of patients with celiac disease in Canada. This process should include gastroenterologists, family physicians and other allied health professionals, including dietitians and celiac support groups.

ACKNOWLEDGEMENT: This study was funded by the Dr JA Campbell Research Fund of the Canadian Celiac Association. Dr Mohsin Rashid is a member of the Professional Advisory Board of the Canadian Celiac Association.

\section{REFERENCES}

1. Fasano A, Berti I, Gerarduzzi T, et al. Prevalence of celiac disease in at-risk and not-at-risk groups in the United States: A large multicenter study. Arch Intern Med 2003;163:286-92.

2. Murray JA, Van Dyke C, Plevak MF, et al. Trends in the identification and clinical features of celiac disease in a North American community, 1950-2001. Clin Gastroenterol Hepatol 2003;1:19-27.

3. Silvester JA, Rashid M. Long-term follow-up of individuals with celiac disease: An evaluation of current practice guidelines. Can J Gastroenterol 2007;21:557-64.

4. American Gastroenterological Association (AGA) Institute medical position statement on the diagnosis and management of celiac disease. Gastroenterology 2006;131:1977-80.

5. British Society for Gastroenterology. Guidelines for the management of patients with coeliac disease, 2002.

$<$ http://www.bsg.org.uk/pdf_word_docs/coeliac.doc $>$ (Accessed on September 29, 2009).

6. Hill ID, Dirks MH, Liptak GS, et al. Guideline for the diagnosis and treatment of celiac disease in children: Recommendations of the North American Society for Pediatric Gastroenterology, Hepatology and Nutrition. J Pediatr Gastroenterol Nutr 2005;40:1-19.

7. National Institutes of Health Consensus Development Conference Statement on Celiac Disease, June 28-30, 2004. Gastroenterology 2005;128(4 Suppl 1):S1-9.

8. Rajan C, ed. Canadian Medical Directory, 53rd edn. Toronto: Scott's Directories, 2007.

9. American Gastroenterological Association medical position statement: Celiac sprue. Gastroenterology 2001;120:1522-5.

10. Cranney A, Zarkadas M, Graham ID, et al. The Canadian celiac health survey. Dig Dis Sci 2007;52:1087-95.

11. Rashid M, Cranney A, Zarkadas M, et al. Celiac disease: Evaluation of the diagnosis and dietary compliance in Canadian children. Pediatrics 2005;116:e754-9.

12. Zarkadas M, Cranney A, Case S, et al. The impact of a gluten-free diet on adults with coeliac disease: Results of a national survey. J Hum Nutr Diet 2006;19:41-9. 
13. Howell E. Physician, count thyself. CMAJ 2008;178:381-4.

14. McGowan KE, Lyon ME, Loken SD, et al. Celiac disease: Are endomysial antibody test results being used appropriately? Clin Chem 2007;53:1775-81.

15. Sinclair D, Duncan H. What happens to patients with positive tissue transglutaminase and endomysium antibody results in general practice? J Clin Pathol 2004;57:943-5.

16. Bebb JR, Lawson A, Knight T, et al. Long-term follow-up of coeliac disease - what do coeliac patients want? Aliment Pharmacol Ther 2006;23:827-31.

17. Zipser RD, Farid M, Baisch D, et al. Physician awareness of celiac disease: A need for further education. J Gen Intern Med 2005;20:644-6.

18. Haines ML, Anderson RP, Gibson PR. Systematic review: The evidence base for long-term management of coeliac disease. Aliment Pharmacol Ther 2008;28:1042-66.

19. Meeuwisse GW. Diagnostic criteria in coeliac disease. Acta Paediatr Scand 1970;59:461.

20. Revised criteria for diagnosis of coeliac disease. Report of working group of European Society of Paediatric Gastroenterology and Nutrition. Arch Dis Child 1990;65:909-11.

21. Bodenheimer T, Lorig K, Holman H, et al. Patient self-management of chronic disease in primary care. JAMA 2002;288:2469-75.
22. Donaldson L. Expert patients usher in a new era of opportunity for the NHS. BMJ 2003;326:1279-80.

23. Catassi C, Kryszak D, Louis-Jacques O, et al. Detection of celiac disease in primary care: A multicenter case-finding study in North America. Am J Gastroenterol 2007;102:1454-60.

24. Annibale B, Severi C, Chistolini A, et al. Efficacy of gluten-free diet alone on recovery from iron deficiency anemia in adult celiac patients. Am J Gastroenterol 2001;96:132-7.

25. Patwari AK, Anand VK, Kapur G, et al. Clinical and nutritional profile of children with celiac disease. Indian Pediatr 2003;40:337-42.

26. Kemppainen TA, Kosma VM, Janatuinen EK, et al. Nutritional status of newly diagnosed celiac disease patients before and after the institution of a celiac disease diet - association with the grade of mucosal villous atrophy. Am J Clin Nutr 1998;67:482-7.

27. Primary Care Society for Gastroenterology. The management of adults with coeliac disease in primary care. May 2006. $<$ http://www.pcsg.org.uk/> (Accessed on September 29, 2009).

28. Pietzak MM. Follow-up of patients with celiac disease: Achieving compliance with treatment. Gastroenterology 2005;128:S135-141. 


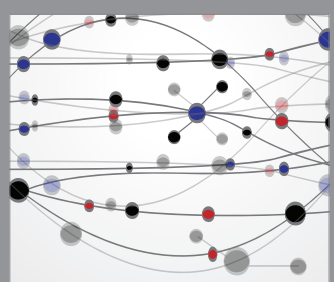

The Scientific World Journal
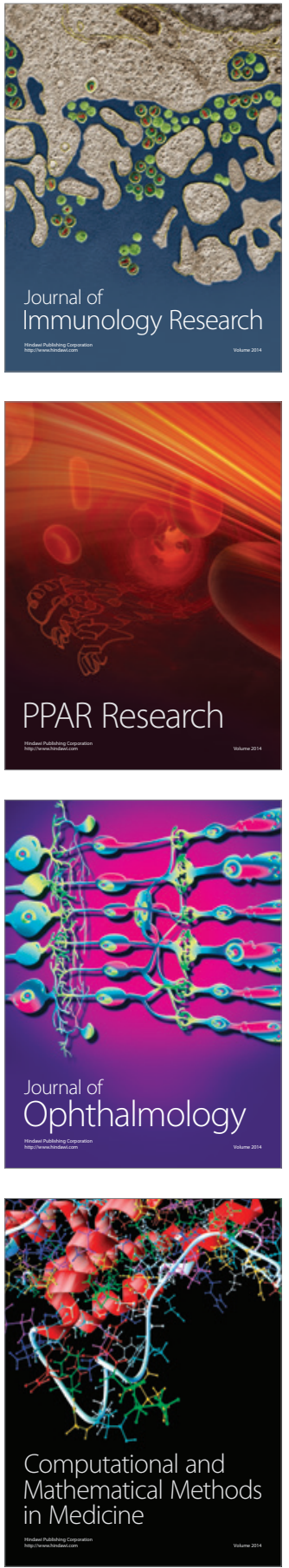

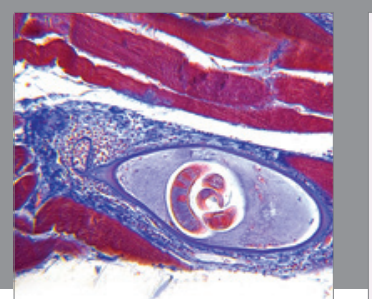

Gastroenterology Research and Practice

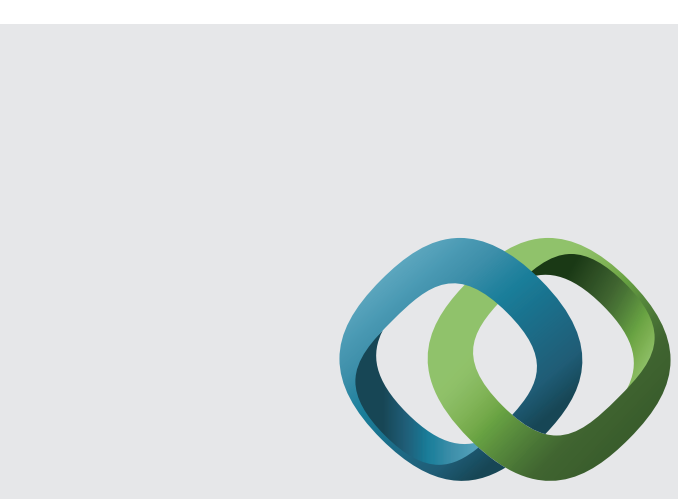

\section{Hindawi}

Submit your manuscripts at

http://www.hindawi.com
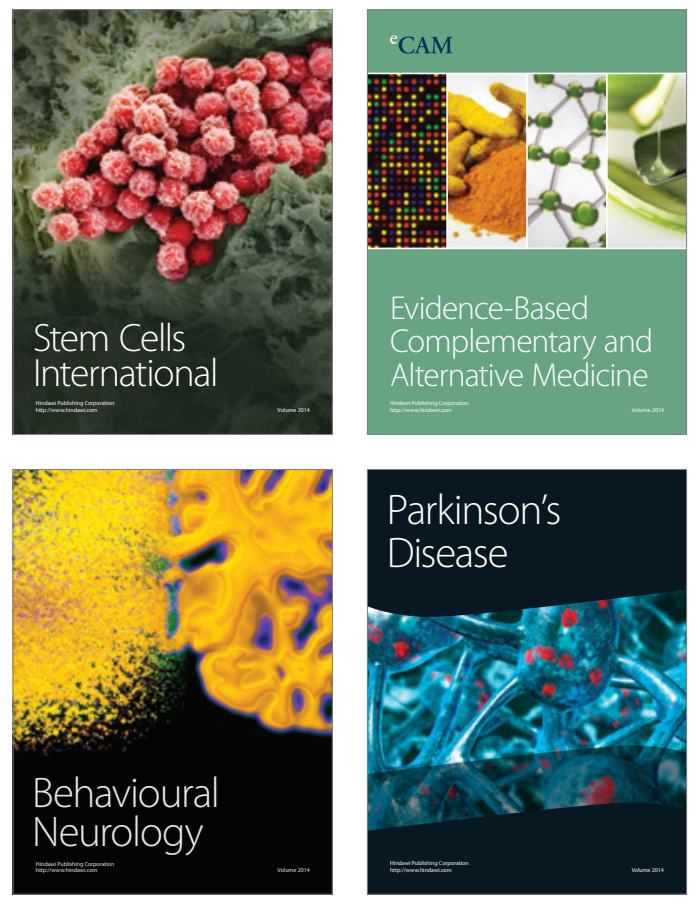
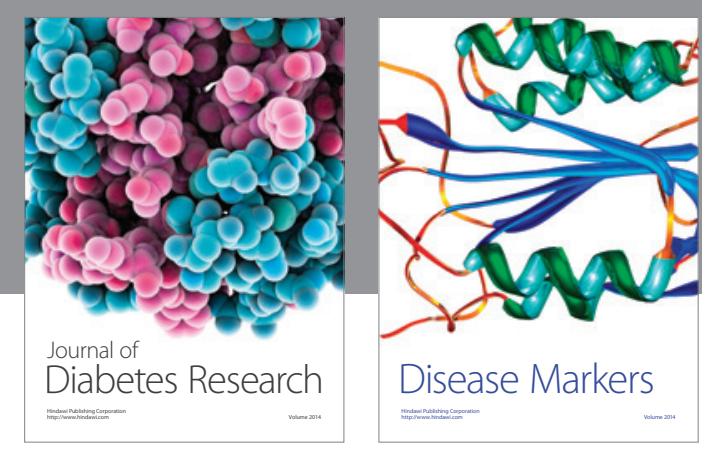

Disease Markers
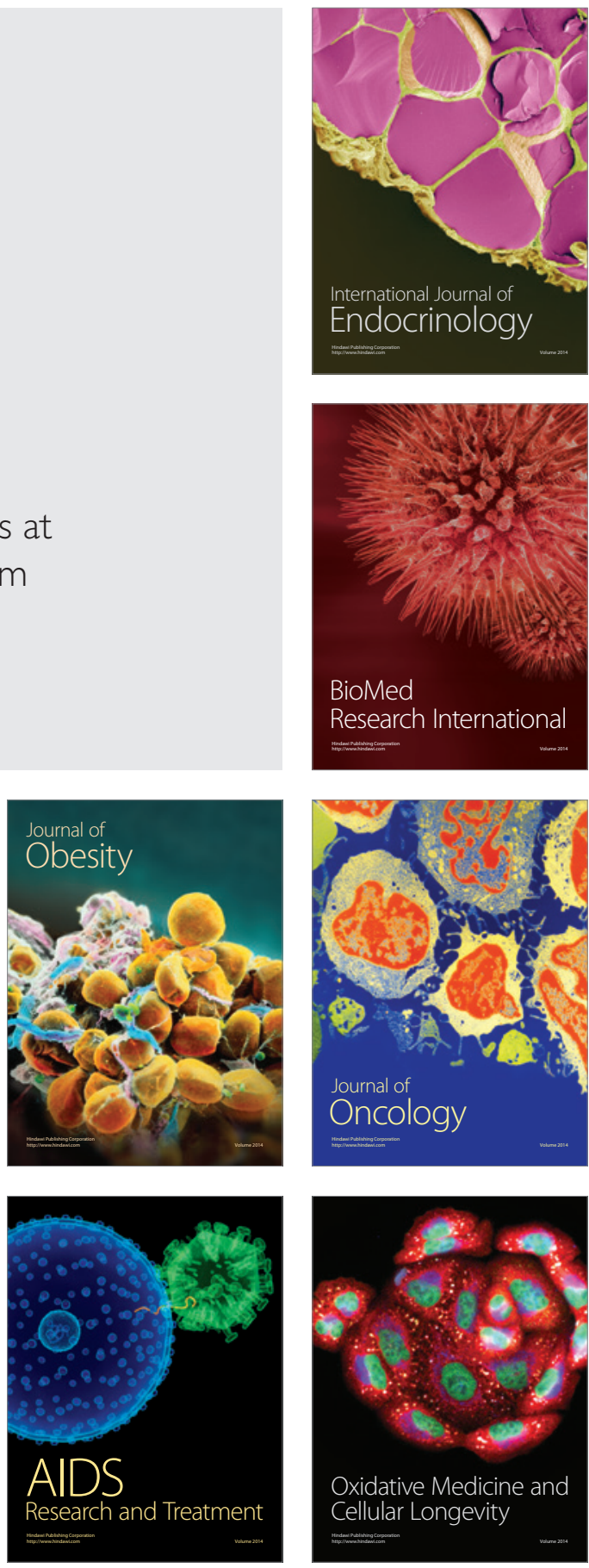